\title{
Preliminary study on the size effect of composite materials subjected to bending
}

\author{
M.Z. Yusof ${ }^{1,2, a}$ \\ ${ }^{1}$ School of Housing, Building and Planning, Universiti Sains Malaysia, 11800, Penang, Malaysia \\ ${ }^{2}$ Perunding Pinang Sdn. Bhd., Suite 111, Kompleks Eureka, 11800, Penang
}

\begin{abstract}
The purpose of this paper is to evaluate the effect of size or dimension changes of reinforced concrete structures, in terms of structural performance and serviceability limit states. A theoretical and design study was carried out to evaluate the structural performance and serviceability of reinforced concrete structures using the European Code of Practice (EC2) and British Code of Practice (BS8110). The analysis required nine different sizes of reinforced concrete beams, with dimension between $150 \mathrm{~mm} \times 250 \mathrm{~mm}$ and $350 \mathrm{~mm} \times 250 \mathrm{~mm}$. The study showed that dimension changes significantly affected the load-carrying capacity and deflection of reinforced concrete members; regardless of their depth/width ratio. The analysis results also produced an equation (presented here) to assess the performance of reinforced concrete members, based on the codes of practice.
\end{abstract}

\section{Introduction}

Concrete deterioration, not only influences durability, but also adversely effects structural integrity or robustness. Deterioration may be the result of design errors, material incompatibilities [1], industrial or farming waste, agro-food and breeding waste waters [2], seawater attack, carbonation, unexpected loads, vibration, repeated freezing and thawing, and the application of de-icer salts throughout winter. Concrete deterioration due to seawater attack (Figure 1) can lead to a dimensional change of concrete sections and then a reduced strength or load carrying capacity of the concrete structure, in terms of ultimate moment. The ultimate moment is the moment produced by the section properties of a beam i.e., effective depth of the beam, compressive strength of the concrete, and the width of the beam [3]. It contrasts with the design moment, which is the moment produced by the permanent load action, or a variable load action, such as imposed, wind, and snow loads etc., which is applied to the beam (as outlined in European Code, EC2). Incompatibilities, in the form of differing strength and modulus elasticity, between repair and substrate concrete can create difficulties. Meanwhile, drying shrinkage of repair materials may reduce longer-term structural efficiency by either initial tensile strain induced in the repair, or due to cracking at the repair or substrate interface [1]. Also, creep of the repair material (under sustained stress) may render the load sharing capacity of the repair less effective over time [4].

\footnotetext{
${ }^{a}$ Corresponding author: zaid_ysf@yahoo.com
} 


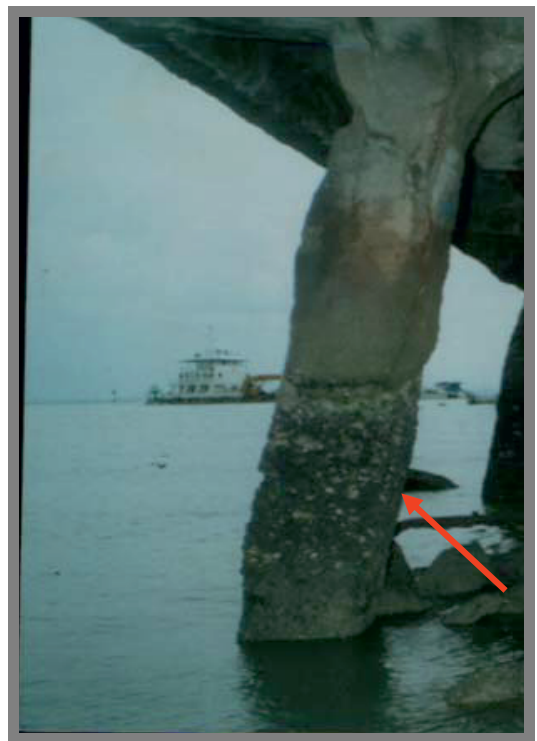

Figure 1. Dimension change of column (arrow)

\section{Size effect investigation}

A simple analogy can be used to explain the effect of dimensional change or decrement on ultimate load, by means of a simply supported beam. The same derivations, with several coefficient of stress changes etc., will also lead to the calculation of ultimate moment, based on European Code (EC2) and British Standard (BS8110) [5]. However, in the derivation of either codes (or another code, such as a Japanese code), the following definition remains the same:

1. The plane transverse sections of the beam remain plane and normal to the longitudinal axis when the beam is bent. This is based on the Bernoulli principle, where distortion or deformation of the concrete surface is negligible.

2. The tensile strength of concrete is negligible.

3. The material of the beam obeys Hooke's law or an elastically-perfect material (Figure 2)

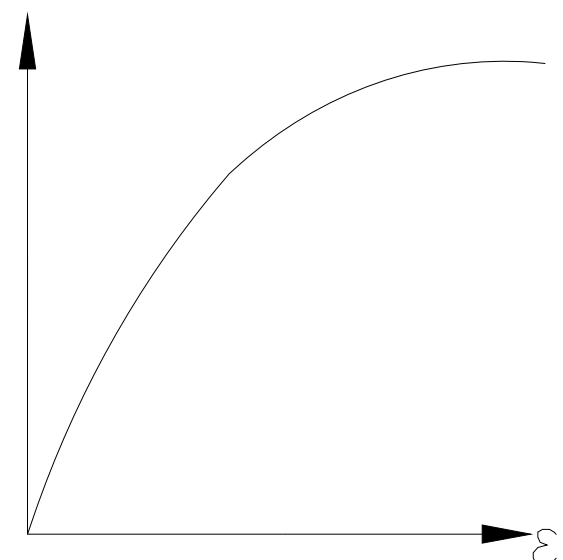

Figure 2. Material yielding plastically after reasonable linear behaviour 


\section{Design outlines}

Two design codes of practice were used to determine the ultimate moment and serviceability of concrete beams with single reinforcement i.e., European Code of practice (EC2) and British Standard code of practice (BS 8110) [5]. In accordance with these codes of practice, the ultimate moment can be calculated as follows:

$$
\begin{aligned}
M_{u} & =0.167 f_{c k} b d^{2}(E C 2, \text { European standard }) \\
M_{u} & =0.156 f_{c u} b d^{2}(E C 2, \text { British standard })
\end{aligned}
$$

Where,

$\mathrm{b} \quad=$ width of the beam section

$\mathrm{d}=$ effective depth of the beam

$\mathrm{f}_{\mathrm{ck}}, \mathrm{f}_{\mathrm{cu}}=$ compressive strength of cylinder and cube, respectively

In order to assess the effect of size or dimension changes of concrete beams, the material's strength, width of section, and deflection coefficient were fixed, whilst the overall depth of sections was varied using different sized beams (see Tables 1 and 2). All concrete beams were analysed as simply supported beams that were subjected to Uniformly Distributed Load (UDL), with a maximum moment at mid-span of $\mathrm{wL}^{2} / 8$ [6]. Furthermore, the evaluation of structural performance was evaluated based on the following design conditions:

\section{(i) Design parameters}

Overall depth of section

Diameter of main bar, $\Phi$

Diameter of links, $\Phi$ '

Cover for exposure, $\mathrm{c}$

Modulus elasticity of concrete, $\mathrm{E}_{\mathrm{c},} \mathrm{E}_{\mathrm{ck}}$

Compressive strength of concrete, $\mathrm{f}_{\mathrm{cu}}, \mathrm{f}_{\mathrm{ck}}$

Depth of tension reinforcement, $d$

Span of concrete beam, $\mathrm{L}$

Total design loads (UDL)

\# referred to design loading for buildings

$$
\begin{array}{ll}
= & \mathrm{h} \\
= & 25 \mathrm{~mm} \\
= & 10 \mathrm{~mm} \\
= & 30 \mathrm{~mm} \\
= & 25 \mathrm{kN} / \mathrm{mm}^{2} \\
= & 30 \mathrm{~N} / \mathrm{mm}^{2} \\
= & \mathrm{h}-\mathrm{c}-\Phi-\Phi / 2 \\
= & 5000 \mathrm{~mm} \\
= & 4 \mathrm{kN} / \mathrm{m \#}
\end{array}
$$

\section{(ii) Serviceability parameters}

The beams supported a uniformly distributed load, w and the deflection of the beam, for the uncracked section, can be calculated as follows:

$$
\text { Deflection, } a=K L^{2} / r_{b}=K L^{2}\left(M / E_{c} I\right)
$$

Where,

$\mathrm{K}=\mathrm{a}$ constant value that depends on the distribution of bending moments in the member

$\mathrm{L}=$ the effective span

$1 / r_{b}=$ the mid-span curvature for beams, or support curvature for cantilevers

$\mathrm{Ec}=$ modulus elastic of concrete

$\mathrm{I}=$ second moment of area

$\mathrm{M}=$ design moments at mid-span

For simply supported beams subjected to a uniformly distributed load (maximum moment $\left.=\mathrm{wL}^{2} / 8\right)$, the deflection coefficient $(\mathrm{K})$ is taken as 0.104 . 


\section{Results}

Analysis results, based on European Code of practice (EC2) and British Standard code of practice (BS 8110 ), are summarised in Tables 1 and 2. The effect of depth/width ratio or dimension change on the ultimate moment capacity, is illustrated in Figures 3 and 4, for EC2 and BS8110, respectively. Serviceability versus size effect at mid-span for the concrete beam is shown in the Figure $\mathbf{5}$. Similarly, the results for ultimate moment versus defLection is presented in Figure 6. From this study, the exponential relationship between dimension change $(\mathrm{h} / \mathrm{b})$ and ultimate moment can be proposed as follows:

$$
\begin{gathered}
M_{u}=10.995 e^{0.2733(h / b)} \quad(E C 2) \\
M_{u}=10.420 e^{0.2717(h / b)}(B S 8110)
\end{gathered}
$$

Table1. Ultimate moment

\begin{tabular}{|c|c|c|c|c|}
\hline $\begin{array}{c}\text { Dimension } \\
\mathbf{( h} \mathbf{x} \mathbf{b}), \mathbf{m m}\end{array}$ & $\mathbf{h} / \mathbf{b}$ & Mu (EC2), $\mathbf{k N m}$ & $\begin{array}{c}\text { Mu (BS8110), } \\
\mathbf{k N m}\end{array}$ & $\begin{array}{c}\text { Design moment } \\
\text { \#\#, kNm }\end{array}$ \\
\hline $150 \times 250 \#$ & 0.6 & 11.9 & 11.1 & 15.3 \\
\hline $175 \times 250$ & 0.7 & 18.7 & 17.6 & 15.8 \\
\hline $200 \times 250$ & 0.8 & 27.2 & 25.5 & 16.3 \\
\hline $225 \times 250$ & 0.9 & 37.3 & 38.8 & 16.7 \\
\hline $250 \times 250$ & 1.0 & 48.9 & 45.6 & 17.2 \\
\hline $275 \times 250$ & 1.1 & 62.0 & 57.9 & 17.7 \\
\hline $300 \times 250$ & 1.2 & 76.7 & 71.9 & 18.1 \\
\hline $325 \times 250$ & 1.3 & 93.0 & 86.9 & 18.6 \\
\hline $350 \times 250$ & 1.4 & 110.9 & 103.9 & 19.1 \\
\hline
\end{tabular}

\#: required tension reinforcement, \#\#: including self weight of beams

Table 2. Serviceability

\begin{tabular}{|c|c|c|c|c|}
\hline $\begin{array}{c}\text { Dimension } \\
(\mathbf{h} \times \mathbf{b}) \mathbf{~ m m}\end{array}$ & $\mathbf{h} / \mathbf{b}$ & $\begin{array}{c}\text { Curvature, } \mathbf{1} / \mathbf{r}_{\mathbf{b}} \\
(\mathbf{\times} \mathbf{1 0}-\mathbf{m m})\end{array}$ & Deflection, $\mathbf{m m}$ & $\begin{array}{c}\text { Deflection } \\
(\mathbf{E C 2} / \mathbf{B S 8 1 1 0})\end{array}$ \\
\hline $150 \times 250 \#$ & 0.6 & 7.25 & $18.9<20 \#$ & OK \\
\hline $175 \times 250$ & 0.7 & 4.71 & 12.2 & OK \\
\hline $200 \times 250$ & 0.8 & 3.25 & 8.5 & OK \\
\hline $225 \times 250$ & 0.9 & 2.35 & 6.1 & OK \\
\hline $250 \times 250$ & 1.0 & 1.76 & 4.6 & OK \\
\hline $275 \times 250$ & 1.1 & 1.36 & 3.5 & OK \\
\hline $300 \times 250$ & 1.2 & 1.07 & 2.8 & OK \\
\hline $325 \times 250$ & 1.3 & 0.86 & 2.3 & OK \\
\hline $350 \times 250$ & 1.4 & 0.71 & 1.9 & OK \\
\hline
\end{tabular}

\#: based on EC2 and BS8110, deflection $=\operatorname{span} / 250$ 


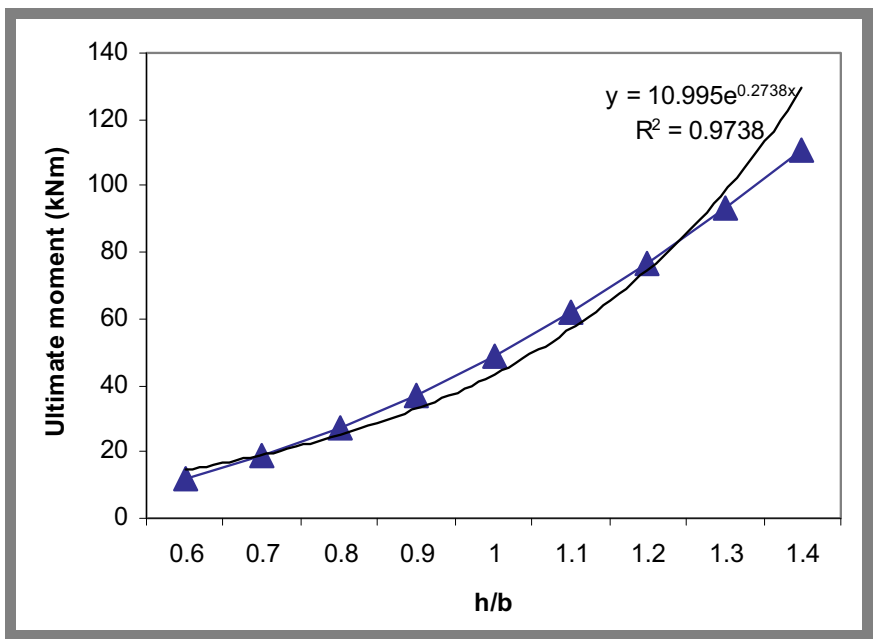

Figure 3 Proposed equation and theoretical ultimate moment (EC2)

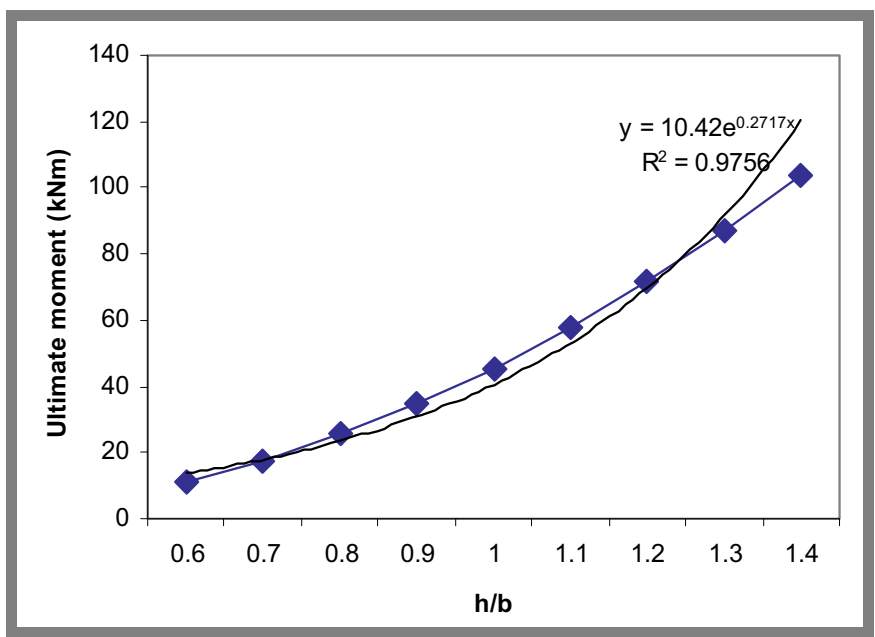

Figure 4 Proposed equation and theoretical ultimate moment (BS8110)

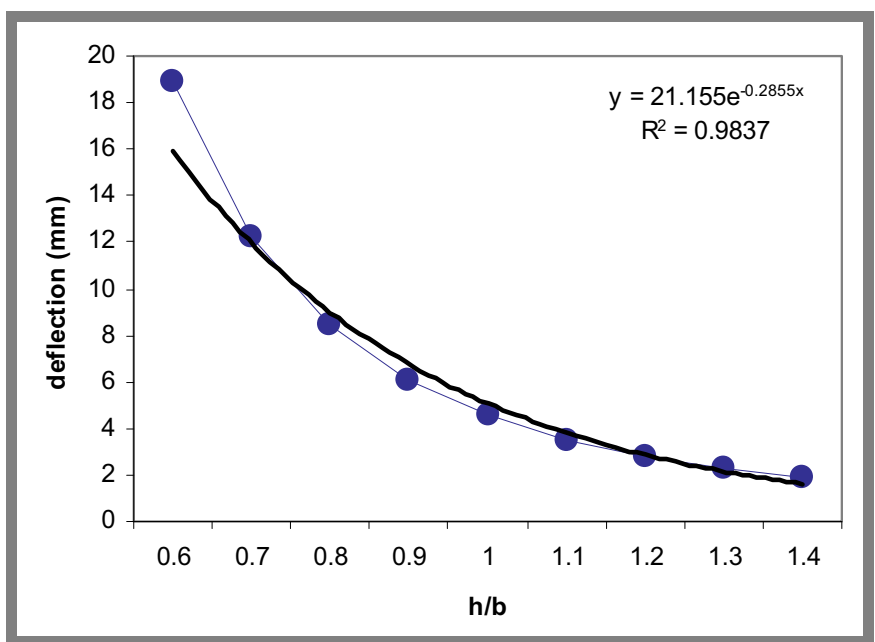

Figure 5 Proposed equation and deflection 


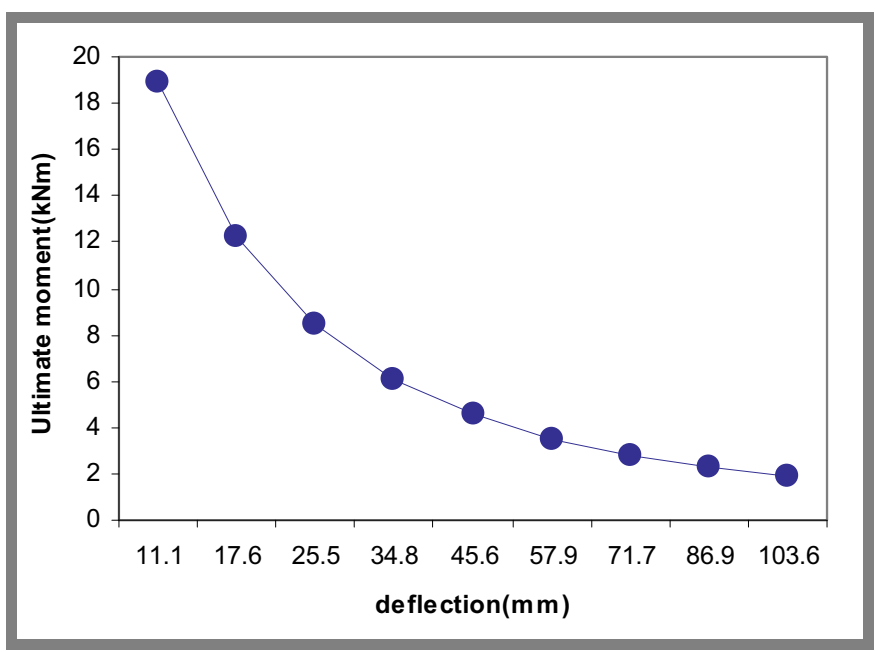

Figure 6 Ultimate moment-deflection relationship

\section{Conclusions}

The theoretical and design study's results show that depth/width ratio or dimension change have significant effects on the ultimate moment capacity and serviceability or deflection of concrete structures. Furthermore, this study reveals that the ultimate moment increases as the $h / b$ of concrete beams increases. However, in terms of serviceability limit state i.e., deflection, it can be seen that the serviceability or deflection of concrete beams decreases as the $\mathrm{h} / \mathrm{b}$ increases. It can be concluded from this study that the effect of dimension change on ultimate moment capacity and serviceability strongly depends on $\mathrm{h} / \mathrm{b}$ ratio and on material properties, such as the compressive strength of concrete, as well as the type of concrete beams reinforcement used.

\section{References}

1. P.S. Mangat, M.K. Limbachiya, Repair material properties which influence long-term performance of concrete structures, Construction and Building Materials, 9 (2) (1995) 81-90

2. C. Magniont, M. Coutand, A. Bertron, X. Cameleyre, C. Lafforgue, S. Beaufort, G. Escadeillas, A new test method to assess the bacterial deterioration of cementitious materials, Cement and Concrete Research 41 (4) (2011) 429-438

3. H. Okamura, Konkurito kozo no genkai jotai sekkei ho (in Japanese), Kyoritsu shuppan kabushikikiasha, Japan, 1984

4. M.A. Tordoff, Assessment of Pre-Stressed concrete bridges suffering from alkali-silica reaction, Cement \& Concrete Composites 12 (3) (1990) 203-210

5. The British Standard Institution, Structural Use of Concrete (BS8110), 1997

6. Y.S. Park, J.K. Suh, J.H. Lee, Y.S. Shin, Strength deterioration of high strength concrete in sulfate environment, Cement and Concrete Research 29 (9) (1999) 1397-1402 